\title{
Thematic role and grammatical function affect pronoun production
}

\author{
Sofiana-Iulia Lindemann, Stanca Mada, Laura Sasu, Madalina Matei \\ Department of Theoretical and Applied Linguistics, Transilvania University of Brasov, \\ Romania \\ https://doi.org/10.36505/ExLing-2020/11/0028/000443
}

\begin{abstract}
According to different approaches to pronoun processing, in pro-drop languages, null pronouns are interpreted as referring back to the grammatical subject and topical referent, while overt pronouns are usually interpreted as coreferring with a non-subject and non-topical antecedent. The present study investigates whether thematic role and grammatical function impact (overt and null) pronoun production in Romania. Results show that we do not encounter a clear division of labour between the two pronoun forms triggered by syntactic structure alone and that thematic roles matter as well. The findings support a multi-dimensional approach, suggesting that different referential forms are constrained by different factors.
\end{abstract}

Keywords: Thematic role, grammatical function, pronoun interpretation, Romanian

\section{Introduction}

Romanian is a pro-drop language (Dobrovie-Sorin 1994), which allows for both overt and covert pronouns in preverbal subject position. According to different studies, null pronouns are used for the most prominent antecedent, while overt pronouns are employed to refer back to a less prominent antecedent (Ariel 1990, Carminati 2002). The prominence or accessibility status of a given referent is affected by grammatical function. Accordingly, the grammatical subject referent is considered prominent and is realized by means of a null pronoun. Other referents that are realized in less prominent positions (e.g. objects) are associated with more elaborated types of referring expressions, such as overt pronouns, definite noun phrases and names.

Besides grammatical function, other factors have been shown to impact the prominence status of a referent and, consequently, the type of referring expression used to refer back to that referent, such as recency, parallelism, topicality (Ariel 1990, Arnold 2001, Chiriacescu 2011b).

Most studies investigating the distribution of pronouns in Romanian were comprehension studies focusing on intra-sentential contexts, exploring whether a null or overt pronoun co-refers with a previously introduced subject or object referent. In this study, we are interested in production preferences: when do writers use an overt pronoun over a null one? And, do the observed biases towards using a pronoun form hold across sentence boundaries? Furthermore,

ExLing 2020: Proceedings of 11 th International Conference of Experimental Linguistics, 12-14 October 2020, Athens, Greece 
114 S.-I. Lindemann, S. Mada, L. Sasu, M. Matei

the present paper focuses on thematic roles and whether they have an impact on pronominalization as well, besides the attested grammatical role preference. In the next sections we present the sentence completion study followed by the conclusions.

\section{The experimental study}

The aim of the present study is to extend the existing literature on accessibility and prominence and, more importantly, to investigate whether thematic role and grammatical function impact (overt and null) pronoun production in Romania.

\section{Participants}

110 native Romanian speakers from the Transilvania University of Brasov, Romania, took part in the experimental study (age range: 18-45 years, mean age 28 years, 65 female). It took about twenty minutes to complete each version of the study.

\section{Design, procedure and materials}

A story completion task was used in which each target sentence consisted of two human referents that had the same gender. As speakers prefer pronoun anaphora when referring back to a previously introduced subject, we used transfer-of-possession-verbs as they allow for the separation of grammatical roles from thematic roles. Some of these verbs realize the Goal as the grammatical subject (e.g. get, CND_3 and CND_4 in Table 1), while others realize the Source in grammatical subject position (e.g. give, CND_1 and CND_2 in Table 1). Participants' task consisted in reading the given onesentence target items and providing natural sounding written continuations to each sentence they read. Furthermore, we specifically asked participants to remention the underlined referent in their continuation sentence (method adapted from Fukumura \& van Gompel 2010). This manipulation resulted in 4 conditions, crossing thematic roles (Goal vs. Source) and grammatical function (Subject vs. Object). We used 36 experimental items, 9 for each condition, and 40 filler items, distributed in two lists.

Table 1. Conditions from the experimental study with English translations.

\begin{tabular}{|l|l|}
\hline CND1_Goal=Object & $\begin{array}{l}\text { Paul i-a dat un bilet lui Andrei. } \\
\text { Paul gave a note to Andrew. }\end{array}$ \\
\hline CND2_Source=Subject & $\begin{array}{l}\text { Paul i-a dat un bilet lui Andrei. } \\
\text { Paul gave a note to Andrew. }\end{array}$ \\
\hline CND3_Goal=Subject & $\begin{array}{l}\text { Raul a cumpărat o carte de la Flavius. } \\
\text { Raul bought a book from Flavius. }\end{array}$ \\
\hline CND4_Source=Object & $\begin{array}{l}\text { Raul a cumpărat o carte de la Flavius. } \\
\text { Raul bought a book from Flavius. }\end{array}$ \\
\hline
\end{tabular}




\section{Results}

The main aim of the study was to assess whether thematic roles affect the production of different types of referring expressions in Romanian alongside the attested grammatical bias. Two independent judges coded for the type of referring expression chosen by the participants to refer back to the underlined referent (i.e. proper name, definite noun phrase, overt pronoun, null pronoun, other). We coded 900 continuations.

Overall, participants used more null pronouns to refer back to the subject referent rather than the non-subject. Overt pronouns were used for both subject and non-subject referents. The preference of the null pronoun to pick up the subject is stronger than the preference of the overt personal pronoun to pick one of the two referents. The findings indicate that we do not find a clear division of labour between the two pronoun forms in terms of syntactic structure.

Interestingly, we found an additional effect of thematic role. This effect was particularly evident for null pronouns, which were more likely to pick up Goal referents than Source referents in subject position. Thus, we found the highest rates of null pronoun use for CND3_Goal=Subject followed by CND2_Source=Subject. In this study, overt pronouns were used more often for the second most prominent referent in terms of both syntactic structure and thematic role. Overt pronouns were used most often for the underlined referents in the CND2_Source=Subject condition, followed by referents introduced in the CND1_Goal=Object condition. Overall, we found most proper names used to pick up the referent in CND2, which was realised as the thematic Source and as the grammatical subject.

\section{Conclusions}

The experimental study revealed two main findings. First, grammatical role has a strong impact on the type of referring expression used. This is in line with previous results that showed that speakers tend to avoid using more elaborated types of referring expressions like names or definite noun phrases for referents recently mentioned in subject position (Ariel 1990, Arnold 1998, Gundel et al. 1993, Chiriacescu 2011b). Instead, they choose reduced types of referring expressions like (overt or null) pronouns.

Second, results showed that the use of a particular thematic role does matter, as it affects the choice of subsequent mention as well (Rosa \& Arnold 2017). Being realised as the grammatical subject referent and simultaneously as the thematic Goal increases the rate of subsequent null pronoun use. The same observation holds for non-subjects realized as the thematic Goal, for which more overt pronouns are subsequently used.

In sum, the present results support a multi-dimensional approach, suggesting that different referential forms are constrained by different grammatical and 
116 S.-I. Lindemann, S. Mada, L. Sasu, M. Matei

semantic factors (Kaiser \& Trueswell 2008; con Heusinger \& Chiriacescu 2009, Chiriacescu 2011a).

\section{Acknowledgements}

This research was supported by a grant of the Romanian Ministery of Research and Innovation, CNCS - UEFISCDI to project PN-III-P1-1.1-TE-2016-1241, within PNCDI III.

\section{References}

Ariel, M. 1990. Accessing noun-phrase antecedents. London, Routledge.

Arnold, J.E. 2001. Reference form and discourse patterns. Unpublished doctoral dissertation. Stanford University, Stanford, CA.

Carminati, M.N. 2002. The processing of Italian subject pronouns. Doctoral dissertation. Retrieved from Proquest (AAI3039345).

Chiriacescu, S.I. 2011a. Effects of reference form on frequency of mention and rate of subsequent mention, In S.L. Devi, A. Branco and R. Mitkov (eds.) 2011, Anaphora Processing and Applications. Lecture Notes in Computer Science, 132-142. Heidelberg, Springer.

Chiriacescu, S.I. 2011b. Factors contributing to the salience of referents. In M. Nevaci (ed.) 2011, Studia linguistica et philologica, 74-96. Bucuresti, Editura Universitatii.

Dobrovie-Sorin, C. 1994. The Syntax of Romanian. Berlin, De Gruyter.

Fukumura, K, van Gompel, R.P.G. 2010. Choosing anaphoric expression. Do people take into account likelihood of reference? Journal of Memory and Language 62, 5266.

Gundel, J., Hedberg, N, Zacharski, R. 1993. Cognitive status and the form of referring expressions in discourse. Language 69(2), 274-307.

von Heusinger, K., Chiriacescu, S.I. 2009. Definite "bare" nouns and pe-marking in Romanian. In Espinal, M.T., Leonetti, M., McNally, L. (eds.) 2009, Proceedings of the IV Nereus International Workshop "Definiteness and DP Structure in Romance Languages", 63-82. Konstanz, Universität Konstanz, Arbeitspapier 124. Fachbereich Sprachwissenschaft.

Kaiser E., Trueswell, J. 2008. Interpreting pronouns and demonstrantives in Finnish: Evidence from a form-specific approach to reference resolution. Language and Cognitive Processes 23(5), 709-748.

Rosa, E., Arnold, J. 2017. Predictability affects production: Thematic roles can affect reference form selection. Journal of Memory and Language 94, 43-60. 